\title{
Nicotinic Acetylcholine Receptors in HIV: Possible Roles During HAND and Inflammation
}

\author{
Coral M. Capó-Vélez ${ }^{1,2}$ - Manuel Delgado-Vélez ${ }^{1,2} \cdot$ Carlos A. Báez-Pagán $^{1,3} \cdot$ José A. Lasalde-Dominicci $^{1,2}$
}

Received: 31 January 2018 / Accepted: 9 July 2018 / Published online: 14 July 2018

(c) The Author(s) 2018

\begin{abstract}
Infection with the human immunodeficiency virus (HIV) remains a threat to global health. Since its discovery, many efforts have been directed at understanding the mechanisms and consequences of infection. Although there have been substantial advances since the advent of antiretroviral therapy, there are still complications that significantly compromise the health of infected patients, particularly, chronic inflammation and HIV-associated neurocognitive disorders (HAND). In this review, a new perspective is addressed in the field of HIV, where the alpha7 nicotinic acetylcholine receptor $(\alpha 7-\mathrm{nAChR})$ is the protagonist. We comprehensively discuss the available evidence implicating $\alpha 7$-nAChRs in the context of HIV and provide possible explanations about its role in HAND and inflammation in both the central nervous system and the periphery.
\end{abstract}

Keywords Nicotinic acetylcholine receptor $\cdot$ HIV $\cdot$ Gp120 · Inflammation · HAND

\section{Introduction}

Despite the success of the combined antiretroviral therapy (cART), infection with the human immunodeficiency virus type 1 (HIV-1) remains a global health threat. cART has helped prolong the lives of patients, improve their life quality, lessen the occurrence of the acquired immunodeficiency syndrome (AIDS), and decrease AIDS and non-AIDSrelated complications; however, it is neither a cure (Spudich 2013) nor is it accessible to every person living with HIV (out of the approximately 36.7 million people infected with the virus, only 18.2 million have access to cART) (Joint United Nations Programme on HIV/AIDS (UNAIDS 2013)).

Coral M. Capó-Vélez and Manuel Delgado-Vélez have contributed equally to this work.

José A. Lasalde-Dominicci

jlasalde@gmail.com

1 Department of Biology, University of Puerto Rico, Río Piedras Campus, PO Box 23360, San Juan, PR 00931, USA

2 Molecular Sciences Research Center, San Juan, PR 00926, USA

3 Department of Physical Sciences, University of Puerto Rico, Río Piedras Campus, PO Box 23323, San Juan, PR 00931, USA
Besides AIDS, HIV infection results in a series of systematic physiological complications such as chronic inflammation and HIV-associated neurocognitive disorders (HAND), regardless of cART treatment (Appay and Sauce 2008; Heaton et al. 2011; Harezlak et al. 2011; Funderburg et al. 2014). These complications do not receive sufficient attention and continue to be a serious threat to the quality of life of patients living with the virus (Saylor et al. 2016; Althoff et al. 2016). Sadly, the mechanisms leading to either of these complications are not completely understood and no specific treatment strategies are available to this date.

Taking this into account, numerous efforts have aimed to better understand the mechanisms used by the virus during infection in order to identify new therapeutic targets. Specifically, several studies have presented evidence implicating ion channels in HIV infection (Raber et al. 1996; Holden et al. 1999; Gelman et al. 2004; Herman et al. 2010; Chen et al. 2011; Liu et al. 2013; Tewari et al. 2015), suggesting that they could be used as potential pharmacological targets. Among these ion channels, nicotinic acetylcholine receptors (nAChRs) have been suggested to play important roles (Bracci et al. 1992; Giunta et al. 2004; González-Lira et al. 2006; Rock et al. 2008; Ballester et al. 2012; Cao et al. 2013; Gundavarapu et al. 2013; Zhang et al. 2015; Báez-Pagán et al. 2015; Ramos et al. 2015; Delgado-Vélez et al. 2015; Liu et al. 2017; Ekins et al. 2017; Capó-Vélez et al. 2018); however, these have not yet been extensively explored. In 
particular, the $\alpha 7$-nAChR is emerging as an important player in the HIV field, since it is expressed not only in the brain, but also in a wide variety of immune cells that are targeted during HIV infection, such as macrophages, monocytes, B-lymphocytes, and T-lymphocytes $\left(\mathrm{CD}^{+}\right.$) (Wang et al. 2003; van der Zanden et al. 2012; Kawashima et al. 2015), making it a suitable target for treatment development.

Due to the presence of $\alpha 7-\mathrm{nAChR}$ on both neuronal and immune cells, and its known participation in HIV settings, this review will focus on the role of $\alpha 7-n A C h R s$ in two different but equally important aspects of HIV: inflammation (neuroinflammation and peripheral inflammation) and HAND, both of which severely compromise the quality of life of patients infected with HIV. Here, we review the role of $\alpha 7$-nAChRs in these HIV-derived consequences and suggest the receptor as a possible pharmacological target to treat/ameliorate both HAND and inflammation.

\section{HIV, CART, and HAND: the Current Status}

HIV infection continues to be a major global public health issue, having claimed more than 35 million lives so far (UNAIDS 2017). The currently available treatment, i.e., cART, has substantially decreased AIDS-related hospital admissions (Center for Disease Control and Prevention 2014) and changed the course of HIV infection from a defining disease to a manageable condition. Consequently, treating patients with cART declined AIDS-related deaths, decreased maternal-infant viral transmission, and decreased the incidence of HIV-associated dementia (HAD) (Maschke et al. 2000; Saylor et al. 2016).

Although cART is greatly beneficial (INSIGHT START Study Group et al. 2015), it has somewhat limited therapeutic results including long-term toxicity, dependence on patient's daily adherence, and drug-drug interactions, among others (Solomon and Sax 2015). In fact, despite the decrease in viral load and improved or normal CD4 $4^{+}$ T-cell counts (Antinori et al. 2007), patients still suffer from chronic inflammation (Appay and Sauce 2008; Funderburg et al. 2014); thus, the need for new and innovative therapies is clearly of the utmost importance.

Inflammation is a defense mechanism against diverse insults, and it is programmed to eliminate or remove exogenous noxious agents. This process is mediated by effector molecules such as cytokines, which are released by immune cells during immune responses. Cytokines are key to innate immune responses; however, excessive cytokine production can give rise to chronic or uncontrolled inflammatory responses, an event related to the pathology of many inflammatory diseases (Johnston and Webster 2009; Wang et al. 2009). Inflammation is controlled through the cholinergic anti-inflammatory pathway (CAP), which seems to be altered in HIV patients (Delgado-Vélez et al. 2015). In non-infected patients, impairment or disruption of the CAP is associated with delirium, depression, ulcerative colitis, postoperative cognitive decline, inflammatory bowel disease, hemorrhagic shock, pancreatitis, exacerbation of ventilator-induced lung injury, septic peritonitis, hypotensive shock, and cardiopulmonary arrest (Lindgren et al. 1993; Borovikova et al. 2000; van Westerloo et al. 2005, 2006; Das 2007; Tracey 2009; dos Santos et al. 2011; Norman et al. 2011, Su et al. 2012; Cerejeira et al. 2012).

Furthermore, around $15-50 \%$ of infected individuals develop some form of cognitive and/or motor dysfunctions, collectively known as HAND (Heaton et al. 2010, 2011; Harezlak et al. 2011; Spudich 2013; McGuire et al. 2014; Saylor et al. 2016). It is a frequent complication of HIV infection that causes several neurological disorders including dementia, myelopathy, peripheral neuropathy, and myopathy (Price and Perry 1994; Lindl et al. 2010). HAND is a heterogeneous complication of HIV, being HAD the most severe form of neurological alteration. At one time, HAD was estimated to affect $20-30 \%$ of infected patients, but after therapies became available and cART was introduced, this percentage decreased significantly (Heaton et al. 2011). cART treatment predominantly shifted HAND neurological manifestations to milder forms of cognitive impairment instead of the frank dementia seen in the pre-cART era (Antinori et al. 2007). Although antiretroviral therapy has been helpful in the treatment of HAD, there is a therapeutic gap within the milder form of the disease, where cART is less effective (McGuire et al. 2014). The milder forms of HAND, minor cognitive dysfunction (MCD), and asymptomatic neurocognitive impairments (ANI), are estimated to affect around $15-50 \%$ of $\mathrm{HIV}^{+}$patients (Simioni et al. 2010; Heaton et al. 2010; Harezlak et al. 2011; Tavazzi et al. 2014; Saylor et al. 2016). This highlights the need to develop innovative pharmacological strategies because therapies aimed to decrease or abrogate HAND cannot necessarily depend on drugs that decrease HIV replication.

The brain is one of the organs most affected by HIV infection (Woods et al. 2009). This reflects the fact that several cells present in the brain, mainly microglia, can be actively infected by HIV since they express receptors needed for infection (Price and Perry 1994). HIV does not infect neurons; however, HAND patients experience a remarkable loss of neurons due to interaction with viral particles, which trigger the release of inflammatory cytokines (Kaul et al. 2001). Neuronal injury is believed to result from a direct effect and/ or interaction between viral proteins and the cell, and indirect effects, which are mediated by activated macrophages that secrete neurotoxic factors such as TNF- $\alpha$, IL- 6 , and IL-1 $\beta$. These neurotoxic factors and/or cytokines can interact with cell surface receptors in neurons and/or astrocytes 
and activate signaling pathways that could lead to apoptosis (Saylor et al. 2016).

Thus, HAND is an important cause of cognitive dysfunction and, together with chronic inflammation, remains an important unresolved issue stemming from HIV. Both are equally important aspects that require urgent attention to counteract their chronic deleterious effects.

\section{Nicotinic Acetylcholine Receptors}

Nicotinic acetylcholine receptors are fast ionotropic ion channel receptors that bind to and are activated by their endogenous ligands acetylcholine ( $\mathrm{ACh}$ ) and choline; they also bind nicotine (Gahring and Rogers 2005). Neuronal nAChRs include $\alpha(\alpha 2-\alpha 10)$ and $\beta$ subunits $(\beta 2-\beta 4)$ arranged in different stoichiometries to form functional receptors (e.g., $\alpha 4 \beta 2, \alpha 2 \beta 2, \alpha 2 \beta 4$, $\alpha 3 \beta 2$, and $\alpha 4 \beta 4$, among others). These heteromeric receptors (assembled with more than one type of subunit) are characteristic for their high affinity to nicotine but differ in their pharmacological properties depending on subunit composition (Gahring and Rogers 2005).

The nAChR subunits $\alpha 2, \alpha 3, \alpha 4, \alpha 10, \beta 2$, and $\beta 4$ are not able to form functional ion channels by themselves. Conversely, subunits $\alpha 7-\alpha 9$ form homomeric receptors (assembled with only one type of subunit) and comprise a family of receptors that bind nicotine with lower affinity than heteromeric receptors but bind the antagonist snake toxin, $\alpha$-bungarotoxin ( $\alpha$-bgtx), with high affinity (Breese et al. 1997; Rangwala et al. 1997). Moreover, studies have shown that nAChRs can modulate cellular processes in the central nervous system (CNS). For instance, nicotine administration can improve cognitive performance in normal subjects and produce a number of physiological effects (Ochoa and Lasalde-Dominicci 2007).

Studies performed by Bracci et al. demonstrated a significant homology between a specific sequence of gp120, the coat protein of HIV, and the putative active sites of snake curare-mimetic neurotoxins, which have the ability to bind irreversibly to nAChRs. Furthermore, the authors demonstrated that recombinant gp120 inhibits the binding of the $\mathrm{nAChR}$ antagonist, $\alpha$-bgtx, suggesting that other type of receptors (such as nAChRs) can function as HIV receptors, and supports the notion that ion channels may have a role during HIV infection. Even though this study suggested a potential role for $\mathrm{nAChRs}$ in HIV, no specific nAChR subtype was implicated (Bracci et al. 1992). Subsequent studies performed in SIV-infected monkeys found that reduced cholinergic neurotransmission was present in the form of a dramatic reduction in choline acetyltransferase activity, the enzyme responsible for the biosynthesis of ACh (Koutsilieri et al. 2000). Consistent with these observations,
González-Lira et al. (2006) performed electrophysiological studies in rats and found that, in addition to motor and cognition impairments, gp120 interferes with cholinergic neurotransmission as part of the neuropsychiatric abnormalities characteristic of HAD. However, nicotine administration maintained these parameters near normality, supporting the participation of nAChRs in the beneficial outcome. An interesting proof-of-concept study was designed and carried out to evaluate if an increase in the bioavailability of $\mathrm{ACh}$, through the chemical inhibition of acetylcholinesterase, was capable of enhancing the anti-inflammatory reflex in patients infected with HIV (Valdés-Ferrer et al. 2009). Results demonstrate that pyridostigmine (an acetylcholinesterase inhibitor) was able to modify the overactivation and proliferation of T-lymphocytes in patients chronically infected with HIV. This approach also led to an increase in the anti-inflammatory cytokine IL-10, a decrease in T-lymphocytes proliferation, and the production of the proinflammatory cytokine IFN- $\gamma$. Moreover, recently, a 16-week proof-of-concept open trial was performed using pyridostigmine as add-on therapy in seven HIV-infected patients with discordant immune response receiving combined antiretroviral therapy, to determine whether pyridostigmine would promote an increase in total $\mathrm{CD} 4^{+}$T-cells (Valdés-Ferrer et al. 2017). Results indicate that in patients suffering from $\mathrm{HIV}^{+}$, add-on pyridostigmine results in a significant and persistent increase in circulating $\mathrm{CD} 4^{+} \mathrm{T}$-cells.

Altogether, these studies suggested a role for $\mathrm{nAChRs}$ in HIV. However, considering the pharmacological properties and different roles of the $\alpha 7-\mathrm{nAChR}$, a closer look is justified. Below we describe the proposed functions/roles of this receptor to then highlight studies specifically relating to HIV-induced inflammation and HAND, where $\alpha 7$-nAChRs play a critical part.

\section{The a7-nAChR: A Unique Ion Channel with Multiple Roles}

Many studies have identified roles in health and disease for the $\alpha 7$-nAChR (Ochoa and Lasalde-Dominicci 2007; Counts et al. 2007; Duffy et al. 2009). The $\alpha 7-n A C h R$ is a ligandgated ion channel that is rapidly desensitized in the presence of a ligand (Conejero-Goldberg et al. 2008). This neuronal receptor is found predominantly in the cerebral cortex, thalamus, hippocampus, basal ganglia, and hypothalamus (both pre- and post-synaptically) (Vázquez-Palacios and BonillaJaime 2004), and immune cells (Wang et al. 2003; Yoshikawa et al. 2006; van der Zanden et al. 2012; Kawashima et al. 2015). Furthermore, $\alpha 7$-nAChRs can be localized in the soma, presynaptic terminals (regulating neurotransmitter release), and postsynaptic terminals (modulating neuronal excitability) (Gahring and Rogers 2005). Once activated, 
its ion pore opens to permit the flow of $\mathrm{Na}^{+}, \mathrm{K}^{+}$, and particularly $\mathrm{Ca}^{2+}$.

The mechanisms by which the $\alpha 7$-nAChR modulates neurotransmitter release and neuronal excitability are distinct from those proposed for other nAChRs and reflect the channel's unique pharmacological properties. For example, the $\alpha 7$-nAChR binds $\alpha$-bgtx with high affinity $(\mathrm{Kd}=94 \mathrm{pM})$ (Rangwala et al. 1997) and has low affinity for agonists such as nicotine (Mansvelder et al. 2009). Furthermore, at low agonist concentrations, activation of $\alpha 7-\mathrm{nAChR}$ induces a $\mathrm{Ca}^{2+}$ influx, leading to a $\mathrm{Ca}^{2+}$-induced $\mathrm{Ca}^{2+}$ release from intracellular stores (Mansvelder et al. 2009).

In general, the proposed function for $\alpha 7$-nAChRs in the brain is to modify the excitability of neurons (Paterson and Nordberg 2000). For example, $\alpha 7$-nAChRs are expressed in the striatum, where they play a role in the function of local neuronal circuits (Martin 2003). A study conducted by Wu et al. (2004) showed that $\alpha 7$-nAChRs are expressed on neurons from the substantia nigra and the ventral tegmental area and demonstrated that, once activated, $\alpha 7$-nAChRs can modulate dopamine release. These results suggest an involvement of the $\alpha 7$-nAChR in dopaminergic neuronal function and drug reinforcement mechanisms, particularly nicotine dependence. Moreover, nicotine stimulates dopamine release in the nucleus accumbens; an effect thought to be mediated by an increase of glutamate release by $\alpha 7-n A C h R s$ located on striatal glutamatergic neurons. This stimulates the release of dopamine in the nucleus accumbens (Kaiser and Wonnacott 2000), further supporting the proposed role of $\alpha 7$-nAChRs as modulators of neurotransmitter release in the CNS. Therefore, $\alpha 7$-nAChRs can modulate various signaling pathways that converge to fine-tune neuronal circuits and contribute to subtle but crucial aspects of cognitive behavior (Mansvelder et al. 2009). Consequently, the expression of small numbers of $\alpha 7$-nAChRs at regulatory sites may lead to multiple outcomes in the performance of normal cells, susceptibility to exogenous agents, or participation in processes ranging from neurodegeneration to inflammation (Gahring and Rogers 2005).

In addition to its central role in the CNS, the $\alpha 7-n A C h R$ is also present in immune cells. As a result, several efforts have been made to elucidate its role in these cells. It is now clear that the $\alpha 7-\mathrm{nAChR}$ is an essential regulator of inflammation in macrophages through the CAP (Tracey 2007). The anti-inflammatory activity of the $\alpha 7-n A C h R$ occurs by the ACh-induced activation of the receptor to inhibit the production of proinflammatory cytokines in macrophages, thereby modulating immune responses and the progression of inflammatory diseases, avoiding organ and systemic damage (Tracey 2009). Altogether, these studies highlight the importance of this neuroimmune tract for the well-being of healthy people and accents the $\alpha 7$-nAChR's pivotal role in the innate immune response necessary to resolve inflammation. Despite its well-known role in the CAP, the lack of functional (electrophysiological) evidence has raised the question of whether this receptor acts as an ion-conducting channel (Skok 2009). However, we recently demonstrated that, in human monocyte-derived macrophages (MDMs), the $\alpha 7$-nAChR retains its ion channel translocation activity (Báez-Pagán et al. 2015). Whether translocated ions play a role in the CAP remains largely unknown (Fig. 1).

Even though the anti-inflammatory role of $\alpha 7$-nAChR in monocytes and macrophages is well recognized (Wang et al. 2003; Yoshikawa et al. 2006), its role in other immune cells is not well understood. Recent reports demonstrate that $\alpha 7$-nAChR plays an essential role in the immune synapse between human T- and B-lymphocytes since they are recruited to these sites to inhibit CD40-related mitogenic functions (Kalashnyk et al. 2012). It also regulates B-lymphocytes' proliferation (Koval et al. 2009), development, and survival (Skok et al. 2006). Moreover, a recent study identified the $\alpha 7-n A C h R$ as a modulator of lymphocyte activation (De Rosa et al. 2009). In the case of regulatory T-lymphocytes (Tregs), the $\alpha 7$-nAChR seems to be a critical regulator of the immunosuppressive function of $\mathrm{CD} 4{ }^{+} \mathrm{CD} 25^{+}$ Tregs (Wang et al. 2010). However, it is also important to mention that, in addition to $\alpha 7$-nAChRs, monocytes, macrophages, B-lymphocytes, and T-lymphocytes also express other homomeric nAChRs, including $\alpha 3, \alpha 5, \alpha 9$, and $\alpha 10$ (Wang et al. 2003; Kawashima et al. 2012), receptors that could contribute to the net cellular response of these cells during health and disease.

As a whole, this demonstrates the importance of $\alpha 7$-nAChRs in various cellular processes and highlights its versatility. Thus, this receptor is an integral player of innate processes ranging from the brain to immune cells having clear repercussions in neurotransmitter release, neurodegenerative diseases, and inflammation.

\section{HIV-Induced Inflammation/ Neuroinflammation and a7-nAChR}

The general notion is that in patients infected with HIV, the inflammatory response is exaggerated, uncontrolled, and chronic. Undoubtedly, patients infected with HIV suffer from chronic and persistent inflammatory processes, which cause numerous AIDS and non-AIDS-related complications such as neurocognitive deterioration, cardiovascular disease, thromboembolic disease, type II diabetes, cancer, osteoporosis, multiple end-organ disease, and frailty (Deeks et al. 2013; Barré-Sinoussi et al. 2013; Hearps et al. 2014), even when patients adhere to cART regimens that minimize viral replication and increase CD4 cell counts (Appay and Sauce 2008; Funderburg et al. 2014). 


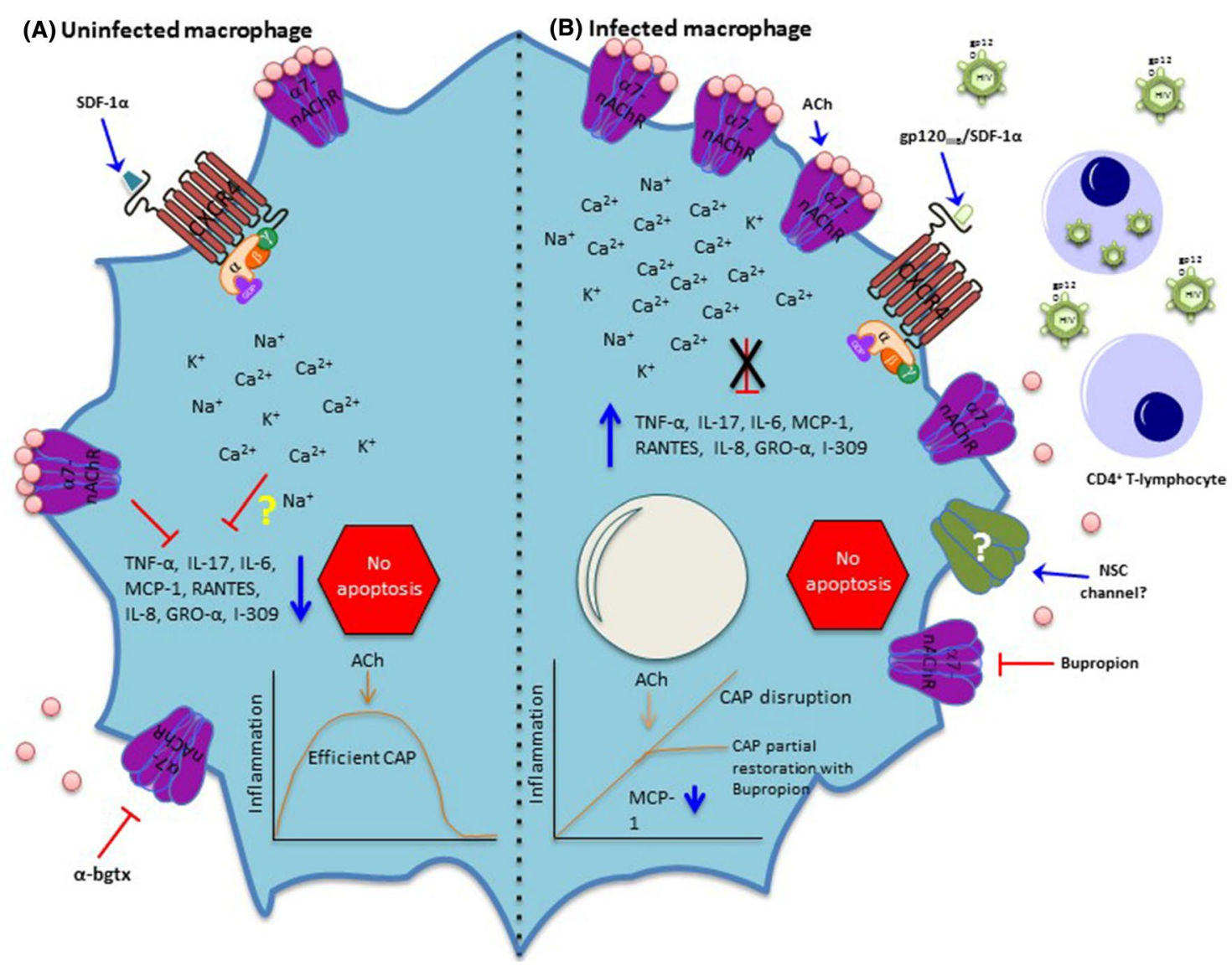

Fig. 1 Effects of HIV infection on macrophages' $\alpha 7$-nAChRs. a In uninfected macrophages, SDF- $1 \alpha$ promotes signaling through CXCR4, a G-protein coupled receptor. In addition, as mentioned before, $\alpha 7-n A C h R$ is sensitive to the antagonist $\alpha$-bgtx. A robust body of evidence demonstrates that the net effect of $\alpha 7-n A C h R$ activation is inhibition of the production of cytokines (Wang et al. 2003), consequently decreasing inflammation (efficient CAP). Whether the ion influx through $\alpha 7-\mathrm{nAChR}$ is relevant for the proper operation of the CAP or other important physiological processes remains obscure. b In infected macrophages, HIV-infected $\mathrm{CD}^{+}$T-lymphocytes secrete virions and gp120 12 IIIB that interact and stimulate CXCR4 to induce the upregulation of $\alpha 7-n A C h R$ (Delgado-Vélez et al. 2015). This upregulation does not result in cell death, or apoptosis, which

In the CNS, the relationship between neuroinflammation and $\alpha 7$-nAChRs in the context of HIV has been scarcely examined. Available evidence suggests that activation of $\alpha 7$-nAChRs expressed by microglia (brain macrophages) plays a key role during neuroinflammation processes since its activation seems to suppress inflammation through the CAP, the same mechanism used by macrophages, thus conferring neuroprotective properties (Shytle et al. 2004; Suzuki et al. 2006). Giunta et al. (2004) reported an in vitro model of HIV-associated dementia composed of cultured microglia cells synergistically activated by IFN- $\gamma$ and gp120. However, this activation was synergistically attenuated through $\alpha 7$-nAChRs and the is consistent with the anti-apoptotic signature expressed by monocytes recovered from patients infected with HIV (Giri et al. 2009) and those from HIV-infected macrophages (Swingler et al. 2007). Contrary to what was expected, the activation of this high number of $\alpha 7$-nAChRs with ACh does not enhance the CAP response because their activation does not lead to inhibition of cytokine production, therefore, conferring macrophages a proinflammatory phenotype indicative of a CAP disruption. Moreover, application of an antagonist of $\alpha 7-n A C h R$, bupropion, partially restores the CAP by reducing inflammatory chemokines, but not interleukins (Delgado-Vélez et al. 2015). Interestingly, whether the identity of the non-selective calcium channel previously described (Liu et al. 2000) is $\alpha 7-n A C h R$ remains to be determined

p44/42 MAPK pathway by pretreatment with nicotine and the cholinesterase inhibitor, galantamine.

The detrimental consequences of HIV infection are not limited to the presence of viral constituents in the body, such as gp120. Accumulating evidence also demonstrates that neuroinflammation could emerge from soluble virions, HIV-infected monocytes, and T-lymphocytes that cross the permeabilized blood-brain barrier (BBB). These infected cells not only affect brain-resident cells upon migration into the CNS but also produce proinflammatory cytokines such as TNF- $\alpha$ and IL- $1 \beta$, which in turn, activate microglia and astrocytes. Cytokine levels in the cerebrospinal fluid are associated with neurocognitive impairment in 
HIV infection. Activated brain-resident cells (e.g., microglia), along with perivascular macrophages, are the main contributors to neuroinflammation in HIV infection (Hong and Banks 2015). They can release neurotoxic factors, such as excitatory amino acids and inflammatory mediators, resulting in neuronal dysfunction and death (Hong and Banks 2015). Moreover, viral proteins (e.g., gp120), which induce brain endothelial cells to release cytokines, may also contribute to brain inflammation and the pathogenesis of HAND. In fact, gp120 facilitates infiltration of HIV-infected immune cells due to permeabilization of the BBB (Kanmogne et al. 2007). Interestingly, a recent study was conducted to evaluate the effects of antiretroviral therapy on the brain. Results showed that indinavir (a protease inhibitor) acts as a positive allosteric modulator of $\alpha 7$-nAChRs at low concentrations, whereas at high concentrations, it acts as an inhibitor of $\alpha 7-n A C h R s$ in the brain, thus possibly contributing to the cognitive dysfunction observed in patients infected with HIV (Ekins et al. 2017). However, caution is needed regarding the possible effects of antiretroviral therapy on the CNS.

Another report on this matter demonstrated that the $\alpha 7$-nAChR agonists, choline, and GTS-21 attenuated the intrathecal gp120-induced proinflammatory cytokine- and microglia-dependent mechanical allodynia (Loram et al. 2010). Of note, choline (full agonist of $\alpha 7-n A C h R$ ) significantly blocked and reversed the gp120-induced mechanical allodynia for at least $4 \mathrm{~h}$ after administration. In addition, intrathecal choline delivered either with or $30 \mathrm{~min}$ after gp120 reduced the gp120-induced production of IL-1 $\beta$ protein and proinflammatory cytokine mRNAs within the lumbar spinal cord. The second $\alpha 7$-nAChR agonist, GTS-21, also significantly reversed the gp120-induced mechanical allodynia and lumbar spinal cord levels of proinflammatory cytokine mRNAs and IL- $1 \beta$ protein.

The CAP is an innate neuroimmune mechanism whereby cytokine production is inhibited via activation of $\alpha 7$-nAChRs expressed in macrophages; this avoids tissue and organ damage due to an exaggerated and persistent inflammation (Tracey 2002; Wang et al. 2009). This pathway provides a fast, discrete, and localized way of controlling immune responses and regulating inflammation (Johnston and Webster 2009) triggered by proinflammatory molecules (e.g., cytokines, LPS). Upon its detection, a signal travels to the CNS via the afferent vagus nerve fibers and stimulates the release of ACh by the efferent arm of the vagus nerve. Then, ACh activates $\alpha 7$-nAChRs in macrophages to inhibit cytokine production and balance the inflammatory response (Tracey 2002, 2009; Wang et al. 2009). In addition, electrical stimulation of the vagus nerve and $\alpha 7$-nAChR agonists ameliorate symptoms in models of inflammatory diseases, demonstrating a pivotal role for $\alpha 7-n A C h R s$ in the regulation of inflammation.
Interestingly, this mechanism is conserved in microglia, where $\alpha 7-n A C h R s$ regulate neuroinflammation (Shytle et al. 2004). Because both macrophages and microglia regulate inflammation through the same mechanism, it could be speculated that they could regulate each other. Indeed, a recent study demonstrates that electrical activation of the vagus nerve decreases the levels of proinflammatory cytokines and the percent of activated microglia in the brain (Meneses et al. 2016). These results provide an important piece of information since neuroinflammation is a hallmark of several infections and neurodegenerative diseases. Thus, strategies to control neuroinflammation could result in a definite improvement in patients (Meneses et al. 2016).

Although the importance of the CAP is evident, so far it has not been studied extensively in patients infected with HIV. Recently, our group examined the cholinergic anti-inflammatory response (CAR) in HIV. We found that gp120 IIIB addition to MDMs induces upregulation of $\alpha 7$-nAChRs in vitro (Fig. 1). Moreover, inflammation studies performed in MDMs pre-exposed to gp $120_{\text {IIIB }}$ and challenged with LPS demonstrated that ACh addition is no longer able to reduce inflammation, suggesting a CAR disruption. Furthermore, examination of $\alpha 7-n A C h R$ levels in monocytes, MDMs, and T-lymphocytes recovered from patients infected with HIV revealed a remarkable upregulation in these cell types (Delgado-Vélez et al. 2015). Finally, application of bupropion (an $\alpha 7-n A C h R$ antagonist) to MDMs upregulated for $\alpha 7-n A C h R$ (by gp120) partially restores the CAR by reducing inflammatory chemokines, but not interleukins (Delgado-Vélez et al. 2015) (Fig. 1).

Overall, HIV-induced inflammation occurs in two scenarios: the periphery and the CNS. Nevertheless, the specific mechanisms by which they occur are not entirely understood, and further studies are needed to identify new therapeutic targets to generate new neuroprotective medications. The studies described here highlight the importance of considering the $\alpha 7$-nAChR and the CAP in HIV-induced pathologies and expand the current knowledge about neuroimmunomodulation processes during HIV infection.

\section{HAND and the a7-nAChR}

The $\alpha 7-\mathrm{nAChR}$ is amply distributed through the brain. In a series of works, the $\alpha 7$-nAChR has been implicated in different HIV-related settings. It was shown that gp120 injected into the hippocampus impairs memory by affecting the cholinergic/vasoactive intestinal peptide system (Farr et al. 2002). More recently, a report implicated $\alpha 7$-nAChRs in Cryptococcal-induced meningitis, the most common fungal opportunistic infection in the CNS of patients infected with HIV(Zhang et al. 2015). Specifically, the authors demonstrated that $\alpha 7-n A C h R s$ play a detrimental role in the host's 
defense against Cryptococcus neoformans and HIV-1 associated comorbidity factors that compromise BBB integrity (Zhang et al. 2015). Furthermore, a recent report suggests that $\alpha 7$-nAChR may play an important role in the neuropathology caused by gp120, methamphetamine, and nicotine, which are the major pathogenic factors contributing to the pathogenesis of HAND (Liu et al. 2017). Moreover, Gundavarapu et al. (2013) demonstrated that HIV-gp120 induces and regulates mucus formation on airway epithelial cells through a CXCR4- $\alpha$ 7-nAChR-GABA ${ }_{\mathrm{A}} \mathrm{R}$-dependent pathway.

In Ballester et al. (2012), a potential role for $\alpha 7-n A C h R$ in HAND was established, as the HIV-1 coat protein gp120 tion of $\alpha 7$-nAChRs promoting an increase in $\mathrm{Ca}^{2+}$ entry that resulted in neuronal cell death (Fig. 2). Along this line, Ramos et al. (2015) showed that, in neuronal cells, gp120 IIIB is able to increase the expression of the $\alpha 7$-nAChR gene, CHRNA7, together with a down-regulation of CHRFAM7A, the partial duplication of the $\alpha 7$-nAChR gene (dup $\alpha 7$ ) (Fig. 2). Moreover, evaluation of these genes in the basal ganglia of patients infected with HIV suffering from different stages of HAND demonstrates an alteration in the CHRFAM7A/CHRNA7 expression ratio. Finally, Capó-Vélez et al. (2018) demonstrated that, in mice expressing gp $120_{\mathrm{IIIB}}$ in the brain, striatal neurons are upregulated for $\alpha 7-\mathrm{nAChRs}$, and its activation leads to an increase in intracellular calcium and eventual apoptosis, an effect that can be attenuated by antagonizing the $\alpha 7$-nAChR (Fig. 2). Moreover, they showed that gp $120_{\text {IIIB }}$ mice perform worse than wild-type mice on a striatum-dependent behavioral task and demonstrate locomotor impairments, which improve significantly with $\alpha 7$-nAChR antagonists (Capó-Vélez et al. 2018).

Taken together, the available literature (summarized in Table 1) highlights the importance of studying the role of the $\alpha 7-n A C h R$ in an HIV-related setting and demonstrates its feasibility as a pharmacological target.

\section{Concluding Remarks}

HIV infection represents a major burden to the immune system. Decades of basic and clinical research have made it clear that HIV infection promotes uncontrolled inflammation in both the periphery and the CNS of infected



Fig. 2 Effects of HIV infection on neurons' $\alpha 7$-nAChRs. 1-4 gp120 released from HIV-infected microglia interact with CXCR4 expressed by neurons, activating the Ras/Raf/MEK/Erk/Egr-1 signaling pathway that eventually promotes $\alpha 7-n A C h R$ upregulation in neuronal cells (Ballester et al. 2012). Moreover, this response can be recapitulated by adding SDF-1 $\alpha$, the endogenous agonist of CXCR4, which also induces $\alpha 7-\mathrm{nAChR}$ overexpression in neuronal cells (Ballester et al. 2012). These responses are sensitive to CXCR4 blockade with AMD3100 and MEK inhibition by U0126 or PD98059. 5 Furthermore, $\alpha 7-n A C h R$ activation with ACh promotes intracellular $\mathrm{Ca}^{2+}$ overload that results in cell death and apoptosis (Ballester et al. 2012; Capó-Vélez et al. 2018). 6 The gp120-induced $\alpha 7$-nAChR upregulation described in points $1-5$ involves a decrease in dup $\alpha 7$ expression, its repressive partial duplication (Ramos et al. 2015) 


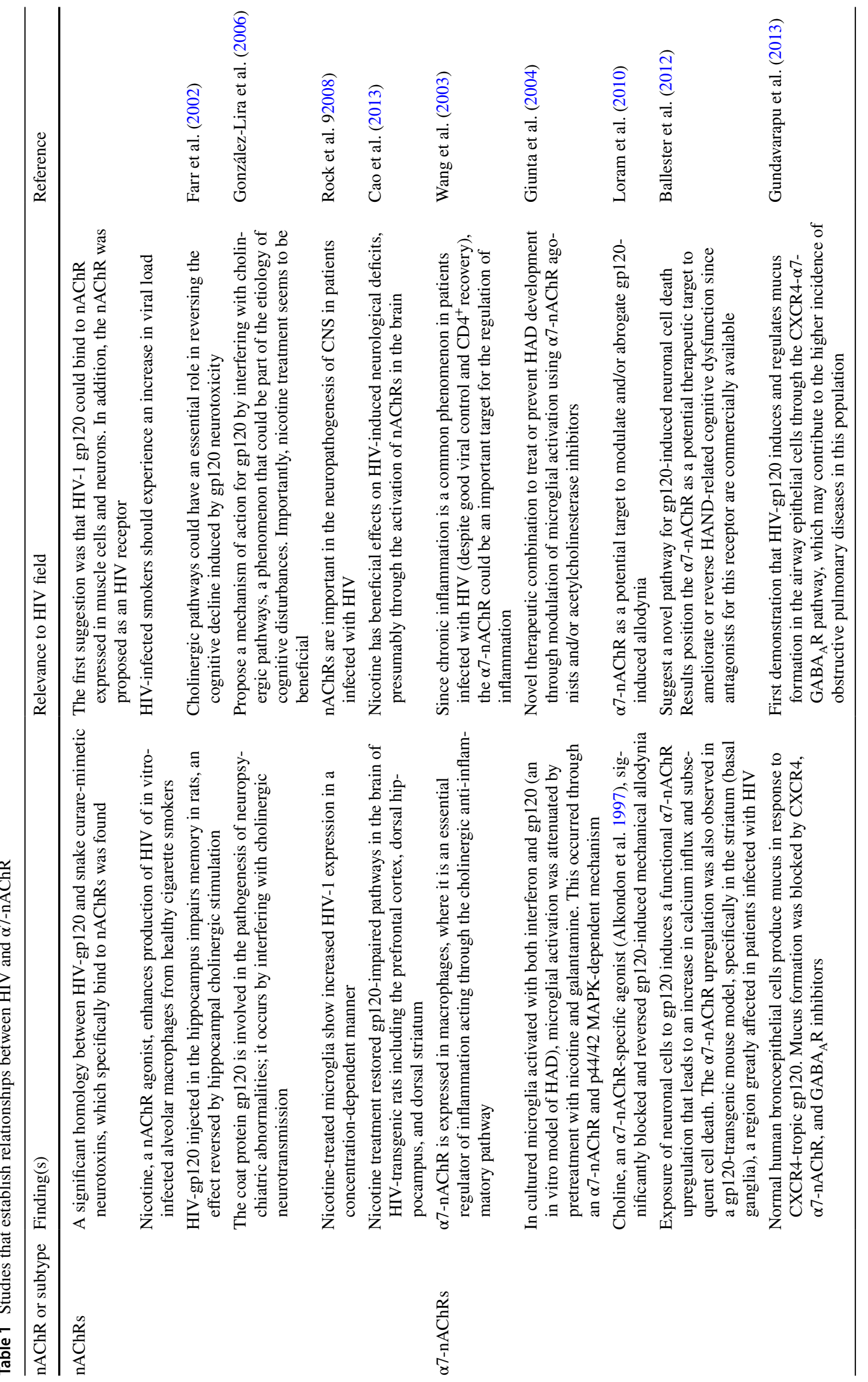




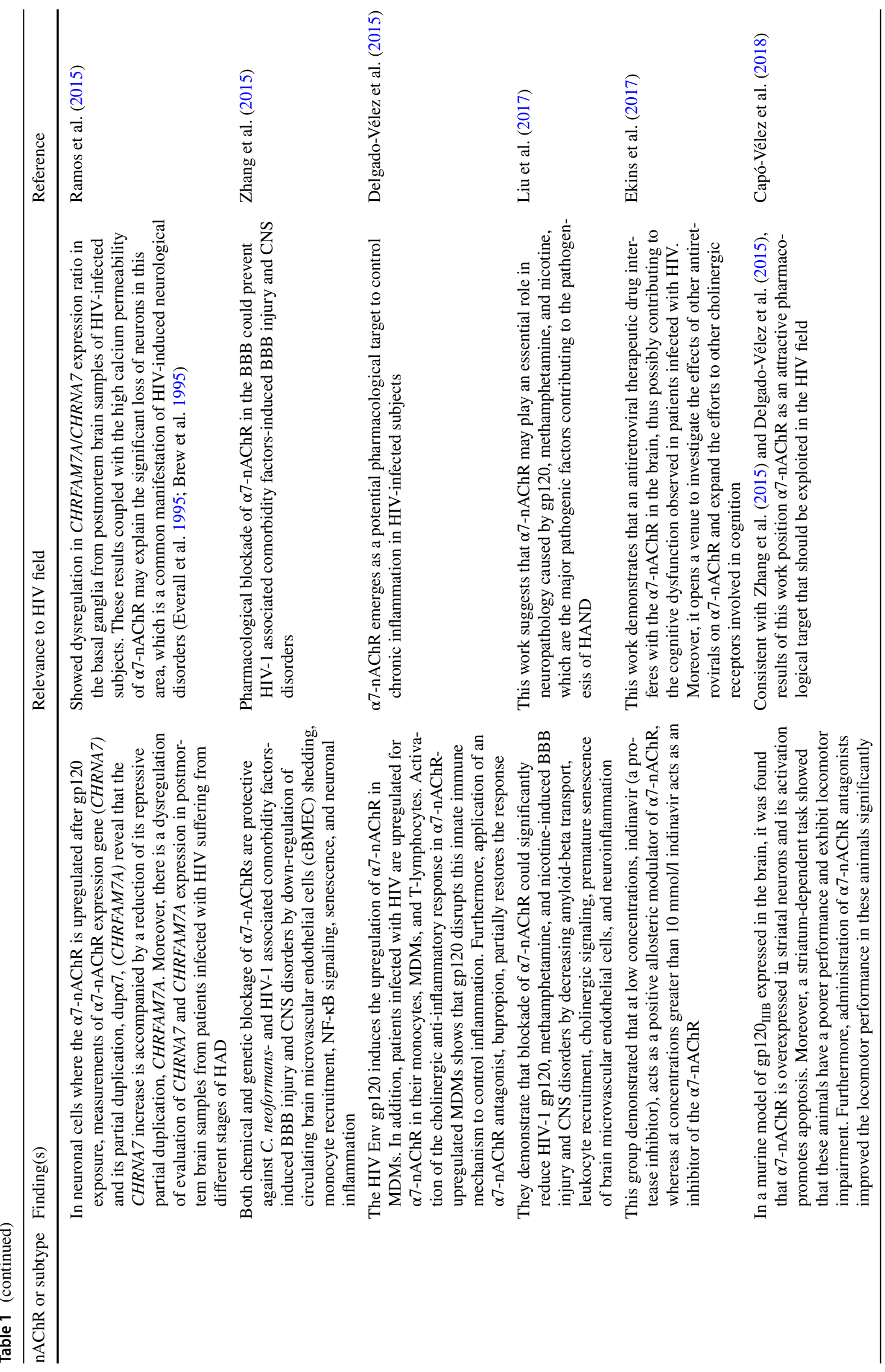


subjects. Furthermore, HIV infection does not only compromise the patient's cognitive functions (as part of HAND development) but also affects peripheral organs as a result of chronic and persistent inflammation. Although significant advances have been made regarding HIV-induced pathologies, an effective adjunctive therapy to mitigate chronic inflammation to avoid damage to organs and/or HAND development remains elusive. The inflammation suffered by patients with HIV represents a major clinical challenge because it is necessary to rectify disproportioned inflammation processes in the CNS and periphery simultaneously. An anti-inflammatory medication that crosses the BBB and acts in the periphery could be an ideal strategy to decrease inflammation on the CNS and periphery in patients infected with HIV. Moreover, a pharmacological target expressed in both CNS and periphery represents a unique opportunity to counteract neuroinflammation/ peripheral inflammation and to prevent HAND as well as the appearance of non-AIDS-related diseases. Indeed, this is what the $\alpha 7$-nAChR offers: a new therapeutic target for adjunctive therapy expressed in the brain and immune cells. In the brain, $\alpha 7$-nAChR activation improves cognitive processes (Thomsen et al. 2010) and decreases neuroinflammation (Egea et al. 2015), whereas in the periphery, $\alpha 7-\mathrm{nAChR}$ activation in macrophages and monocytes inhibits the production of proinflammatory cytokines (Wang et al. 2003; Yoshikawa et al. 2006). The inflammatory process that is developed in the brain of patients infected with HIV has been the focus of recent studies. Neuroinflammation occurs when microglia, astrocytes, and perivascular macrophages are activated. Therefore, $\alpha 7-n A C h R$ clearly represents a unique pharmacological target that could be exploited in the HIV field. Still, it is important to consider that $\alpha 7-\mathrm{nAChR}$ is also expressed in other immune cells such as lymphocytes and other nonimmune cells in which the net effect of its systemic activation, modulation, or blockade is still unknown.

Because the $\alpha 7-\mathrm{nAChR}$ has received much attention by the pharmaceutical industry, many molecules that target this receptor have recently been developed. According to clinicaltrials.gov (consulted June 18, 2017), eleven trials with different drugs targeting $\alpha 7-n A C h R$ have been recently executed, including nine completed, one terminated, and one active (recruiting). In addition to the synthesis of new therapeutics, it is also possible to take advantage of FDA-approved drugs available in the market. For instance, the antidepressant and smoking cessation medication bupropion is an FDA-approved $\alpha 7$-nAChR antagonist that has been used in patients infected with HIV (Park-Wyllie and Antoniou 2003; Currier et al. 2003; Pedrol-Clotet et al. 2006). Importantly, in HIV-negative individuals and animal models, bupropion use has demonstrated anti-inflammatory properties (Altschuler and
Kast 2003; Brustolim et al. 2006). Furthermore, bupropion has been shown to decrease some chemokines, but not interleukins, in human macrophages upregulated for $\alpha 7$-nAChR by the HIV-gp120 IIIB (Delgado-Vélez et al. 2015) (Fig. 1). Indeed, drugs that agonize the $\alpha 7$-nAChR with anti-inflammatory benefits have been described (de Jonge and Ulloa 2007; Pohanka 2012), and new potential compounds continuously emerge (Sahdeo et al. 2014; van Maanen et al. 2015).

Another plausible medication is varenicline, a full agonist of $\alpha 7$-nAChRs (Mihalak et al. 2006) and smoking cessation drug that has been demonstrated to be safe and effective in patients infected with HIV (Cui et al. 2012; Ferketich et al. 2013). Results from varenicline suggest similar or even higher cessation rates than for the general population (Cui et al. 2012; Ferketich et al. 2013; Shirley et al. 2013). Thus, repurposing FDA-approved pharmacotherapeutics targeted at $\alpha 7$-nAChRs to treat HIV-associated diseases implies that new treatments could reach patients faster.

An understudied perspective on HIV-induced chronic inflammation and HAND is the role of nAChRs. Here, we provide evidence demonstrating that the $\alpha 7-\mathrm{nAChR}$ is upregulated in HIV settings in a gp120-dependent manner in both neural and immune cells (Ballester et al. 2012; Ramos et al. 2015; Delgado-Vélez et al. 2015; Capó-Vélez et al. 2018) and that HIV-infected monocytes, macrophages, and T-cells are also upregulated in HIV-infected women (Delgado-Vélez et al. 2015). The observed increase in $\alpha 7$-nAChR levels is in accordance with the $\alpha 7$-nAChR upregulation reported under inflammation settings in T-lymphocytes, alveolar macrophages, and neutrophils (Su et al. 2007; Chernyavsky et al. 2009; Nizri et al. 2009). Apparently, $\alpha 7$-nAChR upregulation is a typical response of immune cells during inflammation challenges, whereas in the CNS it appears to be a response induced by the HIV viral glycoprotein, gp120 (Ballester et al. 2012; Capó-Vélez et al. 2018) or the viral presence itself. Overall, the $\alpha 7$-nAChR offers the opportunity to explore new pharmacological treatments through the development of new drugs or by testing available drugs for HIV treatment.

It is not clear whether high levels of $\alpha 7-n A C h R s$ in immune or neuronal cells (particularly microglia and macrophages) represent an anti-inflammatory ally that can be exploited as a therapeutic target since our recent results demonstrate that upregulation of $\alpha 7-n A C h R s$ does not potentiate the anti-inflammatory response in macrophages (DelgadoVélez et al. 2015). Moreover, whether the upregulation observed in neural cells and neural tissues (Ballester et al. 2012; Ramos et al. 2015; Capó-Vélez et al. 2018) represents a pharmacological intervention opportunity remains undetermined. However, positive allosteric modulators of $\alpha 7$-nAChRs, such as PNU-120596, can be tested to try to rescue $\alpha 7$-nAChR's anti-inflammatory activity (Hurst 
et al. 2005). Thus, efforts to better understand the molecular mechanism that impede the appropriate function of the cholinergic anti-inflammatory response in macrophages in HIV settings are definitely critical in the development of new strategies to reduce neuroinflammation and peripheral inflammation in patients infected with HIV. Moreover, more research is necessary to better understand the role of $\alpha 7-\mathrm{nAChR}$ in the neurocognitive deterioration experienced by patients infected with HIV.

Acknowledgements This work was supported by National Institutes of Health-NINDS (Grant No. 2U54NS43011) and COBRE (Grant No. 1P20GM103642) to JA.L-D, RISE Program (Grant No. 2R25GM061151) to M.D-V and C.M.C-V. The project described was supported by Award Number 2U54MD007587 from the National Institute on Minority Health and Health Disparities and Award Number P30MH075673 from the National Institute of Mental Health to C.A.B$\mathrm{P}$. The content is solely the responsibility of the authors and does not necessarily represent the official views of the National Institutes of Health.

Author Contributions Both C.M.C-V. and M.D-V. performed literature research and wrote the review. J.A.L-D. and C.A.B-P. helped with the conceptualization of the review and performed literature research.

\section{Compliance with Ethical Standards}

Conflict of interest The authors declare that there is no conflict of interest.

Open Access This article is distributed under the terms of the Creative Commons Attribution 4.0 International License (http://creativeco mmons.org/licenses/by/4.0/), which permits unrestricted use, distribution, and reproduction in any medium, provided you give appropriate credit to the original author(s) and the source, provide a link to the Creative Commons license, and indicate if changes were made.

\section{References}

Alkondon M, Pereira EF, Cortes WS et al (1997) Choline is a selective agonist of alpha7 nicotinic acetylcholine receptors in the rat brain neurons. Eur J Neurosci 9:2734-2742

Althoff KN, Smit M, Reiss P, Justice AC (2016) HIV and ageing: improving quantity and quality of life. Curr Opin HIV AIDS 11:527-536. https://doi.org/10.1097/COH.0000000000000305

Altschuler EL, Kast RE (2003) Bupropion in psoriasis and atopic dermatitis: decreased tumor necrosis factor-alpha? Psychosom Med 65:719

Antinori A, Arendt G, Becker JT et al (2007) Updated research nosology for HIV-associated neurocognitive disorders. Neurology 69:1789-1799. https://doi.org/10.1212/01.WNL.0000287431 $.88658 .8 \mathrm{~b}$

Appay V, Sauce D (2008) Immune activation and inflammation in HIV-1 infection: causes and consequences. J Pathol 214:231241. https://doi.org/10.1002/path.2276

Báez-Pagán CA, Delgado-Vélez M, Lasalde-Dominicci JA (2015) Activation of the macrophage $\alpha 7$ nicotinic acetylcholine receptor and control of inflammation. J Neuroimmune Pharmacol
Off J Soc NeuroImmune Pharmacol 10:468-476. https://doi. org/10.1007/s11481-015-9601-5

Ballester LY, Capó-Vélez CM, García-Beltrán WF et al (2012) Up-regulation of the neuronal nicotinic receptor $\alpha 7$ by HIV glycoprotein 120: potential implications for HIV-associated neurocognitive disorder. J Biol Chem 287:3079-3086. https:// doi.org/10.1074/jbc.M111.262543

Barré-Sinoussi F, Ross AL, Delfraissy J-F (2013) Past, present and future: 30 years of HIV research. Nat Rev Microbiol 11:877883. https://doi.org/10.1038/nrmicro3132

Borovikova LV, Ivanova S, Zhang M et al (2000) Vagus nerve stimulation attenuates the systemic inflammatory response to endotoxin. Nature 405:458-462. https://doi.org/10.1038/35013070

Bracci L, Lozzi L, Rustici M, Neri P (1992) Binding of HIV-1 gp120 to the nicotinic receptor. FEBS Lett 311:115-118

Breese CR, Adams C, Logel J et al (1997) Comparison of the regional expression of nicotinic acetylcholine receptor alpha7 mRNA and $\left[{ }^{125} \mathrm{I}\right]$-alpha-bungarotoxin binding in human postmortem brain. J Comp Neurol 387:385-398

Brew BJ, Rosenblum M, Cronin K, Price RW (1995) AIDS dementia complex and HIV-1 brain infection: clinical-virological correlations. Ann Neurol 38:563-570. https://doi.org/10.1002/ ana.410380404

Brustolim D, Ribeiro-dos-Santos R, Kast RE et al (2006) A new chapter opens in anti-inflammatory treatments: the antidepressant bupropion lowers production of tumor necrosis factoralpha and interferon-gamma in mice. Int Immunopharmacol 6:903-907. https://doi.org/10.1016/j.intimp.2005.12.007

Cao J, Wang S, Wang J et al (2013) RNA deep sequencing analysis reveals that nicotine restores impaired gene expression by viral proteins in the brains of HIV-1 transgenic rats. PloS ONE 8:e68517. https://doi.org/10.1371/journal.pone.0068517

Capó-Vélez CM, Morales-Vargas B, García-González A et al (2018) The alpha7-nicotinic receptor contributes to gp120-induced neurotoxicity: implications in $\mathrm{HIV}$-associated neurocognitive disorders. Sci Rep 8:1829. https://doi.org/10.1038/s41598-01820271-x

Center for Disease Control and Prevention (2014) HIV surveillance report 2012

Cerejeira J, Nogueira V, Luís P et al (2012) The cholinergic system and inflammation: common pathways in delirium pathophysiology. J Am Geriatr Soc 60:669-675. https://doi.org/10.111 $1 / \mathrm{j} .1532-5415.2011 .03883 . \mathrm{x}$

Chen L, Liu J, Xu C et al (2011) HIV-1gp120 induces neuronal apoptosis through enhancement of 4-aminopyridine-senstive outward $\mathrm{K}^{+}$currents. PloS ONE 6:e25994. https://doi. org/10.1371/journal.pone.0025994

Chernyavsky AI, Arredondo J, Galitovskiy V et al (2009) Structure and function of the nicotinic arm of acetylcholine regulatory axis in human leukemic T cells. Int J Immunopathol Pharmacol 22:461-472

Conejero-Goldberg C, Davies P, Ulloa L (2008) Alpha7 nicotinic acetylcholine receptor: a link between inflammation and neurodegeneration. Neurosci Biobehav Rev 32:693-706. https:// doi.org/10.1016/j.neubiorev.2007.10.007

Counts SE, He B, Che S et al (2007) Alpha7 nicotinic receptor upregulation in cholinergic basal forebrain neurons in Alzheimer disease. Arch Neurol 64:1771-1776. https://doi.org/10.1001/ archneur.64.12.1771

Cui Q, Robinson L, Elston D et al (2012) Safety and tolerability of varenicline tartrate (Champix $(\circledR) / C h a n t i x(\circledR))$ for smoking cessation in HIV-infected subjects: a pilot open-label study. AIDS Patient Care STDs 26:12-19. https://doi.org/10.1089/ apc.2011.0199 
Currier MB, Molina G, Kato M (2003) A prospective trial of sustainedrelease bupropion for depression in HIV-seropositive and AIDS patients. Psychosomatics 44:120-125

Das UN (2007) Vagus nerve stimulation, depression, and inflammation. Neuropsychopharmacology 32:2053-2054. https://doi. org/10.1038/sj.npp.1301286

De Jonge WJ, Ulloa L (2007) The alpha7 nicotinic acetylcholine receptor as a pharmacological target for inflammation. Br J Pharmacol 151:915-929. https://doi.org/10.1038/sj.bjp.0707264

De Rosa MJ, Dionisio L, Agriello E et al (2009) Alpha 7 nicotinic acetylcholine receptor modulates lymphocyte activation. Life Sci 85:444-449. https://doi.org/10.1016/j.lfs.2009.07.010

Deeks SG, Tracy R, Douek DC (2013) Systemic effects of inflammation on health during chronic HIV infection. Immunity 39:633645. https://doi.org/10.1016/j.immuni.2013.10.001

Delgado-Vélez M, Báez-Pagán CA, Gerena Y et al (2015) The $\alpha 7$-nicotinic receptor is upregulated in immune cells from HIV-seropositive women: consequences to the cholinergic antiinflammatory response. Clin Transl Immunol 4:e53. https://doi. org/10.1038/cti.2015.31

Dos Santos CC dos, Shan Y, Akram A et al (2011) Neuroimmune regulation of ventilator-induced lung injury. Am J Respir Crit Care Med 183:471-482. https://doi.org/10.1164/rccm.20100 2-0314OC

Duffy AM, Zhou P, Milner TA, Pickel VM (2009) Spatial and intracellular relationships between the alpha7 nicotinic acetylcholine receptor and the vesicular acetylcholine transporter in the prefrontal cortex of rat and mouse. Neuroscience 161:1091-1103. https://doi.org/10.1016/j.neuroscience.2009.04.024

Egea J, Buendia I, Parada E et al (2015) Anti-inflammatory role of microglial alpha7 nAChRs and its role in neuroprotection. Biochem Pharmacol 97:463-472. https://doi.org/10.1016/j. bcp.2015.07.032

Ekins S, Mathews P, Saito EK et al (2017) $\alpha 7$-Nicotinic acetylcholine receptor inhibition by indinavir: implications for cognitive dysfunction in treated HIV disease. AIDS Lond Engl 31:1083-1089. https://doi.org/10.1097/QAD.0000000000001488

Everall I, Barnes H, Spargo E, Lantos P (1995) Assessment of neuronal density in the putamen in human immunodeficiency virus (HIV) infection. Application of stereology and spatial analysis of quadrats. J Neurovirol 1:126-129

Farr SA, Banks WA, Uezu K et al (2002) Mechanisms of HIV type 1-induced cognitive impairment: evidence for hippocampal cholinergic involvement with overstimulation of the VIPergic system by the viral coat protein core. AIDS Res Hum Retrovir 18:1189-1195. https://doi.org/10.1089/08892220260387931

Ferketich AK, Diaz P, Browning KK et al (2013) Safety of varenicline among smokers enrolled in the lung HIV study. Nicotine Tob Res 15:247-254. https://doi.org/10.1093/ntr/nts121

Funderburg NT, Jiang Y, Debanne SM et al (2014) Rosuvastatin treatment reduces markers of monocyte activation in HIV-infected subjects on antiretroviral therapy. Clin Infect Dis 58:588-595. https://doi.org/10.1093/cid/cit748

Gahring LC, Rogers SW (2005) Neuronal nicotinic acetylcholine receptor expression and function on nonneuronal cells. AAPS J 7:E885-E894. https://doi.org/10.1208/aapsj070486

Gelman BB, Soukup VM, Schuenke KW et al (2004) Acquired neuronal channelopathies in HIV-associated dementia. J Neuroimmunol 157:111-119. https://doi.org/10.1016/j.jneur oim.2004.08.044

Giri MS, Nebozyhn M, Raymond A et al (2009) Circulating monocytes in HIV-1-infected viremic subjects exhibit an antiapoptosis gene signature and virus- and host-mediated apoptosis resistance. J Immunol Baltim Md 1950 182:4459-4470. https://doi. org/10.4049/jimmunol.0801450
Giunta B, Ehrhart J, Townsend K et al (2004) Galantamine and nicotine have a synergistic effect on inhibition of microglial activation induced by HIV-1 gp120. Brain Res Bull 64:165-170. https:// doi.org/10.1016/j.brainresbull.2004.06.008

González-Lira B, Rueda-Orozco PE, Galicia O et al (2006) Nicotine prevents HIVgp120-caused electrophysiological and motor disturbances in rats. Neurosci Lett 394:136-139. https://doi. org/10.1016/j.neulet.2005.10.021

Gundavarapu S, Mishra NC, Singh SP et al (2013) HIV gp120 induces mucus formation in human bronchial epithelial cells through CXCR4/ $/ 7$-nicotinic acetylcholine receptors. PloS ONE 8:e77160. https://doi.org/10.1371/journal.pone.0077160

Harezlak J, Buchthal S, Taylor M et al (2011) Persistence of HIV-associated cognitive impairment, inflammation, and neuronal injury in era of highly active antiretroviral treatment. AIDS Lond Engl 25:625-633. https://doi.org/10.1097/QAD.0b013e3283427da7

Hearps AC, Martin GE, Rajasuriar R, Crowe SM (2014) Inflammatory co-morbidities in HIV + individuals: learning lessons from healthy ageing. Curr HIV/AIDS Rep 11:20-34. https://doi. org/10.1007/s11904-013-0190-8

Heaton RK, Clifford DB, Franklin DR et al (2010) HIV-associated neurocognitive disorders persist in the era of potent antiretroviral therapy: CHARTER Study. Neurology 75:2087-2096. https:// doi.org/10.1212/WNL.0b013e318200d727

Heaton RK, Franklin DR, Ellis RJ et al (2011) HIV-associated neurocognitive disorders before and during the era of combination antiretroviral therapy: differences in rates, nature, and predictors. J Neurovirol 17:3-16. https://doi.org/10.1007/s1336 5-010-0006-1

Herman BD, Votruba I, Holy A et al (2010) The acyclic 2,4-diaminopyrimidine nucleoside phosphonate acts as a purine mimetic in HIV-1 reverse transcriptase DNA polymerization. J Biol Chem 285:12101-12108. https://doi.org/10.1074/jbc.M109.096529

Holden CP, Haughey NJ, Nath A, Geiger JD (1999) Role of $\mathrm{Na}^{+} / \mathrm{H}^{+}$ exchangers, excitatory amino acid receptors and voltage-operated $\mathrm{Ca}^{2+}$ channels in human immunodeficiency virus type 1 gp120mediated increases in intracellular $\mathrm{Ca}^{2+}$ in human neurons and astrocytes. Neuroscience 91:1369-1378

Hong S, Banks WA (2015) Role of the immune system in HIVassociated neuroinflammation and neurocognitive implications. Brain Behav Immun 45:1-12. https://doi.org/10.1016/j. bbi.2014.10.008

Hurst RS, Hajós M, Raggenbass M et al (2005) A novel positive allosteric modulator of the alpha7 neuronal nicotinic acetylcholine receptor: in vitro and in vivo characterization. $\mathbf{J}$ Neurosci 25:4396-4405. https://doi.org/10.1523/JNEUR OSCI.5269-04.2005

INSIGHT START Study Group, Lundgren JD, Babiker AG et al (2015) Initiation of antiretroviral therapy in early asymptomatic HIV infection. N Engl J Med 373:795-807. https://doi.org/10.1056/ NEJMoa1506816

Johnston GR, Webster NR (2009) Cytokines and the immunomodulatory function of the vagus nerve. Br J Anaesth 102:453-462. https://doi.org/10.1093/bja/aep037

Joint United Nations Programme on HIV/AIDS (UNAIDS (2013) Global report: UNAIDS report on global AIDS epidemic 2013

Kaiser S, Wonnacott S (2000) alpha-bungarotoxin-sensitive nicotinic receptors indirectly modulate $[(3) \mathrm{H}]$ dopamine release in rat striatal slices via glutamate release. Mol Pharmacol 58:312-318

Kalashnyk OM, Gergalova GL, Komisarenko SV, Skok MV (2012) Intracellular localization of nicotinic acetylcholine receptors in human cell lines. Life Sci 91:1033-1037. https://doi. org/10.1016/j.lfs.2012.02.005

Kanmogne GD, Schall K, Leibhart J et al (2007) HIV-1 gp120 compromises blood-brain barrier integrity and enhance monocyte 
migration across blood-brain barrier: implication for viral neuropathogenesis. J Cereb Blood Flow Metab 27:123-134. https:// doi.org/10.1038/sj.jcbfm. 9600330

Kaul M, Garden GA, Lipton SA (2001) Pathways to neuronal injury and apoptosis in HIV-associated dementia. Nature 410:988-994. https://doi.org/10.1038/35073667

Kawashima K, Fujii T, Moriwaki Y, Misawa H (2012) Critical roles of acetylcholine and the muscarinic and nicotinic acetylcholine receptors in the regulation of immune function. Life Sci 91:1027-1032. https://doi.org/10.1016/j.lfs.2012.05.006

Kawashima K, Fujii T, Moriwaki Y et al (2015) Non-neuronal cholinergic system in regulation of immune function with a focus on $\alpha 7 \mathrm{nAChRs}$. Int Immunopharmacol 29:127-134. https://doi. org/10.1016/j.intimp.2015.04.015

Koutsilieri E, Czub S, Scheller C et al (2000) Brain choline acetyltransferase reduction in SIV infection. An index of early dementia? Neuroreport 11:2391-2393

Koval LM, Yu Lykhmus O, Omelchenko DM et al (2009) The role of alpha7 nicotinic acetylcholine receptors in B lymphocyte activation. Ukr Biokhimicheskiı̌ Zhurnal 81:5-11

Lindgren S, Stewenius J, Sjölund K et al (1993) Autonomic vagal nerve dysfunction in patients with ulcerative colitis. Scand J Gastroenterol 28:638-642

Lindl KA, Marks DR, Kolson DL, Jordan-Sciutto KL (2010) HIVassociated neurocognitive disorder: pathogenesis and therapeutic opportunities. J Neuroimmune Pharmacol 5:294-309. https://doi. org/10.1007/s11481-010-9205-z

Liu QH, Williams DA, McManus C et al (2000) HIV-1 gp120 and chemokines activate ion channels in primary macrophages through CCR5 and CXCR4 stimulation. Proc Natl Acad Sci USA 97:4832-4837. https://doi.org/10.1073/pnas.090521697

Liu H, Liu J, Liang S, Xiong H (2013) Plasma gelsolin protects HIV-1 gp120-induced neuronal injury via voltage-gated $\mathrm{K}^{+}$channel Kv2.1. Mol Cell Neurosci 57:73-82

Liu L, Yu J, Li L et al (2017) Alpha7 nicotinic acetylcholine receptor is required for amyloid pathology in brain endothelial cells induced by Glycoprotein 120 , methamphetamine and nicotine. Sci Rep 7:40467. https://doi.org/10.1038/srep40467

Loram LC, Harrison JA, Chao L et al (2010) Intrathecal injection of an alpha seven nicotinic acetylcholine receptor agonist attenuates gp120-induced mechanical allodynia and spinal pro-inflammatory cytokine profiles in rats. Brain Behav Immun 24:959-967. https://doi.org/10.1016/j.bbi.2010.03.008

Mansvelder HD, Mertz M, Role LW (2009) Nicotinic modulation of synaptic transmission and plasticity in cortico-limbic circuits. Semin Cell Dev Biol 20:432-440. https://doi.org/10.1016/j. semcdb.2009.01.007

Martin JH (2003) Neuroanatomy: text and atlas, 3rd edn. McGraw-Hill Companies, New York

Maschke M, Kastrup O, Esser S et al (2000) Incidence and prevalence of neurological disorders associated with HIV since the introduction of highly active antiretroviral therapy (HAART). J Neurol Neurosurg Psychiatry 69:376-380

McGuire JL, Barrett JS, Vezina HE et al (2014) Adjuvant therapies for HIV-associated neurocognitive disorders. Ann Clin Transl Neurol 1:938-952. https://doi.org/10.1002/acn3.131

Meneses G, Bautista M, Florentino A et al (2016) Electric stimulation of the vagus nerve reduced mouse neuroinflammation induced by lipopolysaccharide. J Inflamm 13:33. https://doi.org/10.1186/ s12950-016-0140-5

Mihalak KB, Carroll FI, Luetje CW (2006) Varenicline is a partial agonist at alpha4beta2 and a full agonist at alpha7 neuronal nicotinic receptors. Mol Pharmacol 70:801-805. https://doi.org/10.1124/ mol.106.025130

Nizri E, Irony-Tur-Sinai M, Lory O et al (2009) Activation of the cholinergic anti-inflammatory system by nicotine attenuates neuroinflammation via suppression of Th1 and Th17 responses. J Immunol Baltim Md 1950 183:6681-6688. https://doi. org/10.4049/jimmunol.0902212

Norman GJ, Morris JS, Karelina K et al (2011) Cardiopulmonary arrest and resuscitation disrupts cholinergic anti-inflammatory processes: a role for cholinergic $\alpha 7$ nicotinic receptors. J Neurosci 31:3446-3452. https://doi.org/10.1523/JNEUR OSCI.4558-10.2011

Ochoa ELM, Lasalde-Dominicci J (2007) Cognitive deficits in schizophrenia: focus on neuronal nicotinic acetylcholine receptors and smoking. Cell Mol Neurobiol 27:609-639. https://doi. org/10.1007/s10571-007-9149-x

Park-Wyllie LY, Antoniou T (2003) Concurrent use of bupropion with CYP2B6 inhibitors, nelfinavir, ritonavir and efavirenz: a case series. AIDS Lond Eng1 17:638-640. https://doi. org/10.1097/01.aids.0000050846.71999.ff

Paterson D, Nordberg A (2000) Neuronal nicotinic receptors in the human brain. Prog Neurobiol 61:75-111

Pedrol-Clotet E, Deig-Comerma E, Ribell-Bachs M et al (2006) Bupropion use for smoking cessation in HIV-infected patients receiving antiretroviral therapy. Enfermedades Infecc Microbiol Clínica 24:509-511

Pohanka M (2012) Alpha7 nicotinic acetylcholine receptor is a target in pharmacology and toxicology. Int J Mol Sci 13:2219-2238. https://doi.org/10.3390/ijms13022219

Price RW, Perry SW (1994) HIV, AIDS, and the brain. Raven Press Ltd, New York

Raber J, Toggas SM, Lee S et al (1996) Central nervous system expression of HIV-1 Gp120 activates the hypothalamic-pituitary-adrenal axis: evidence for involvement of NMDA receptors and nitric oxide synthase. Virology 226:362-373. https:// doi.org/10.1006/viro.1996.0664

Ramos FM, Delgado-Vélez M, Ortiz ÁL et al (2015) Expression of CHRFAM7A and CHRNA7 in neuronal cells and postmortem brain of HIV-infected patients: considerations for HIVassociated neurocognitive disorder. J Neurovirol. https://doi. org/10.1007/s13365-015-0401-8

Rangwala F, Drisdel RC, Rakhilin S et al (1997) Neuronal alphabungarotoxin receptors differ structurally from other nicotinic acetylcholine receptors. J Neurosci 17:8201-8212

Rock RB, Gekker G, Aravalli RN et al (2008) Potentiation of HIV-1 expression in microglial cells by nicotine: involvement of transforming growth factor-beta 1. J Neuroimmune Pharmacol 3:143-149. https://doi.org/10.1007/s11481-007-9098-7

Sahdeo S, Wallace T, Hirakawa R et al (2014) Characterization of RO5126946, a Novel $\alpha 7$ nicotinic acetylcholine receptor-positive allosteric modulator. J Pharmacol Exp Ther 350:455-468. https://doi.org/10.1124/jpet.113.210963

Saylor D, Dickens AM, Sacktor N et al (2016) HIV-associated neurocognitive disorder-pathogenesis and prospects for treatment. Nat Rev Neurol 12:234-248. https://doi.org/10.1038/ nrneurol.2016.27

Shirley DK, Kaner RJ, Glesby MJ (2013) Effects of smoking on nonAIDS-related morbidity in HIV-infected patients. Clin Infect Dis 57:275-282. https://doi.org/10.1093/cid/cit207

Shytle RD, Mori T, Townsend K et al (2004) Cholinergic modulation of microglial activation by alpha 7 nicotinic receptors. J Neurochem 89:337-343. https://doi.org/10.104 6/j.1471-4159.2004.02347.x

Simioni S, Cavassini M, Annoni J-M et al (2010) Cognitive dysfunction in HIV patients despite long-standing suppression of viremia. AIDS Lond Eng1 24:1243-1250. https://doi. org/10.1097/QAD.0b013e3283354a7b

Skok MV (2009) Editorial: To channel or not to channel? Functioning of nicotinic acetylcholine receptors in leukocytes. J Leukoc Biol 86:1-3. https://doi.org/10.1189/JLB.0209106 
Skok M, Grailhe R, Agenes F, Changeux J-P (2006) The role of nicotinic acetylcholine receptors in lymphocyte development. J Neuroimmunol 171:86-98. https://doi.org/10.1016/j.jneur oim.2005.09.011

Solomon DA, Sax PE (2015) Current state and limitations of daily oral therapy for treatment. Curr Opin HIV AIDS 10:219-225. https:// doi.org/10.1097/COH.0000000000000165

Spudich S (2013) HIV and neurocognitive dysfunction. Curr HIV/AIDS Rep 10:235-243. https://doi.org/10.1007/s1190 4-013-0171-y

Su X, Lee JW, Matthay ZA et al (2007) Activation of the alpha7 $\mathrm{nAChR}$ reduces acid-induced acute lung injury in mice and rats. Am J Respir Cell Mol Biol 37:186-192. https://doi.org/10.1165/ rcmb.2006-0240OC

Su X, Feng X, Terrando N et al (2012) Dysfunction of inflammationresolving pathways is associated with exaggerated postoperative cognitive decline in a rat model of the metabolic syndrome. Mol Med Camb Mass 18:1481-1490. https://doi.org/10.2119/molme d.2012.00351

Suzuki T, Hide I, Matsubara A et al (2006) Microglial alpha7 nicotinic acetylcholine receptors drive a phospholipase C/IP3 pathway and modulate the cell activation toward a neuroprotective role. J Neurosci Res 83:1461-1470. https://doi.org/10.1002/jnr.20850

Swingler S, Mann AM, Zhou J et al (2007) Apoptotic killing of HIV1 -infected macrophages is subverted by the viral envelope glycoprotein. PLoS Pathog 3:1281-1290. https://doi.org/10.1371/ journal.ppat.0030134

Tavazzi E, Morrison D, Sullivan P et al (2014) Brain inflammation is a common feature of HIV-infected patients without HIV encephalitis or productive brain infection. Curr HIV Res 12:97-110

Tewari M, Monika null, Varghse RK et al (2015) Astrocytes mediate HIV-1 Tat-induced neuronal damage via ligand-gated ion channel P2×7R. J Neurochem 132:464-476. https://doi.org/10.1111/ jnc. 12953

Thomsen MS, Hansen HH, Timmerman DB, Mikkelsen JD (2010) Cognitive improvement by activation of alpha7 nicotinic acetylcholine receptors: from animal models to human pathophysiology. Curr Pharm Des 16:323-343

Tracey KJ (2002) The inflammatory reflex. Nature 420:853-859. https ://doi.org/10.1038/nature01321

Tracey KJ (2007) Physiology and immunology of the cholinergic antiinflammatory pathway. J Clin Investig 117:289-296. https://doi. org/10.1172/JCI30555

Tracey KJ (2009) Reflex control of immunity. Nat Rev Immunol 9:418428. https://doi.org/10.1038/nri2566

UNAIDS (2017) Fact sheet - Latest statistics on the status of the AIDS epidemic. https://www.unaids.org/en/resources/fact-sheet . Accessed 12 July 2018

Valdés-Ferrer SI, Crispín JC, Belaunzarán PF et al (2009) Acetylcholine-esterase inhibitor pyridostigmine decreases $\mathrm{T}$ cell overactivation in patients infected by HIV. AIDS Res Hum Retrovir 25:749-755. https://doi.org/10.1089/aid.2008.0257

Valdés-Ferrer SI, Crispín JC, Belaunzarán-Zamudio PF et al (2017) Add-on pyridostigmine enhances $\mathrm{CD} 4^{+} \mathrm{T}$-cell recovery in
HIV-1-infected immunological non-responders: a proof-ofconcept study. Front Immunol 8:1301. https://doi.org/10.3389/ fimmu.2017.01301

Van Westerloo DJ, Giebelen IAJ, Florquin S et al (2005) The cholinergic anti-inflammatory pathway regulates the host response during septic peritonitis. J Infect Dis 191:2138-2148. https://doi. org/10.1086/430323

Van Westerloo DJ, Giebelen IA, Florquin S et al (2006) The vagus nerve and nicotinic receptors modulate experimental pancreatitis severity in mice. Gastroenterology 130:1822-1830. https://doi. org/10.1053/j.gastro.2006.02.022

Van Maanen MA, Papke RL, Koopman FA et al (2015) Two novel $\alpha 7$ nicotinic acetylcholine receptor ligands: in vitro properties and their efficacy in collagen-induced arthritis in mice. PloS ONE 10:e0116227. https://doi.org/10.1371/journal.pone.0116227

Van der Zanden EP, Hilbers FW, Verseijden C et al (2012) Nicotinic acetylcholine receptor expression and susceptibility to cholinergic immunomodulation in human monocytes of smoking individuals. Neuroimmunomodulation 19:255-265. https://doi. org/10.1159/000335185

Vázquez-Palacios G, Bonilla-Jaime H (2004) Nicotine acetylcholine receptors and neuropsychiatric disorders. Rev Neurol 39:1146-1160

Wang H, Yu M, Ochani M et al (2003) Nicotinic acetylcholine receptor alpha7 subunit is an essential regulator of inflammation. Nature 421:384-388. https://doi.org/10.1038/nature01339

Wang D, Zhou R, Yao Y (2009) Role of cholinergic anti-inflammatory pathway in regulating host response and its interventional strategy for inflammatory diseases. Chin J Traumatol 12:355-364

Wang D, Zhou R, Yao Y et al (2010) Stimulation of $\alpha 7$ nicotinic acetylcholine receptor by nicotine increases suppressive capacity of naturally occurring $\mathrm{CD} 4^{+} \mathrm{CD} 25^{+}$regulatory $\mathrm{T}$ cells in mice in vitro. J Pharmacol Exp Ther 335:553-561. https://doi. org/10.1124/jpet.110.169961

Woods SP, Moore DJ, Weber E, Grant I (2009) Cognitive neuropsychology of HIV-associated neurocognitive disorders. Neuropsychol Rev 19:152-168. https://doi.org/10.1007/s1106 5-009-9102-5

Wu J, George AA, Schroeder KM et al (2004) Electrophysiological, pharmacological, and molecular evidence for alpha7-nicotinic acetylcholine receptors in rat midbrain dopamine neurons. J Pharmacol Exp Ther 311:80-91. https://doi.org/10.1124/ jpet.104.070417

Yoshikawa H, Kurokawa M, Ozaki N et al (2006) Nicotine inhibits the production of proinflammatory mediators in human monocytes by suppression of I-kappaB phosphorylation and nuclear factorkappaB transcriptional activity through nicotinic acetylcholine receptor alpha7. Clin Exp Immunol 146:116-123. https://doi.org /10.1111/j.1365-2249.2006.03169.x

Zhang B, Yu J-Y, Liu L-Q et al (2015) Alpha7 nicotinic acetylcholine receptor is required for blood-brain barrier injury-related CNS disorders caused by Cryptococcus neoformans and HIV-1 associated comorbidity factors. BMC Infect Dis 15:352. https://doi. org/10.1186/s12879-015-1075-9 